DEATH BY ELECTRIC CURRENTS AND BY LIGH'TNING. ${ }^{1}$

Death by Electric Currents.

I BELIEVE that no loss of human life from indus1 trial currents of electricity occurred before 1879 , though currents strong enough to have caused death were employed in lighting the operatic stage in Paris (at the first pirformance of Meyerbeer's "Le Prophète") so lon s ago as 1849, and in lighthouses on and off the coast of England in 1857. In 1879 a stage carpenter was killed at Lyons by the alternating current of a Siemens dynamo that was giving a voltage of about 250 volts at the time. The man became insensible at once, and died in twenty minutes; artificial respiration was not applied. The first death in this country took place at a theatre in Aston, outside Birmingham, in 1880 , where a bandsman shortcircuited a powerful electric battery, became insensible, and died in forty minutes. Since that date the annual number of deaths from electric shock has steadily increased, particularly during this century, in which the industrial employment of electricity has extended so widely, and is now quite large. In the ten years I90I-1o the Registrar-General's returns show a total of 183 such deaths in England and Wales, the population having risen from $32 \frac{1}{2}$ to 36 million during that period. In the three years Igor to 1903 there were twenty-five deaths; in 1908 , twenty-five; in Igog, twenty-nine; in Igro, twenty-six. Only two of these $\mathrm{I}_{3}$ victims were females, because women are so much less exposed to contact with dangerous electric currents than are men. Many deaths by electricity occur annually on the Continent, though I can only bring forward a few scattered figures to prove it. In Germany, thirty-three were killed in 1908; fifty-two in 1909; forty-six in 19r1. In Austria eleven were killed by electricity in 1907; ten in IqIO; ten in IgII. In Switze:land, twentyone were killed in 1905; nineteen in 1906. I think it probable that about 200 persons are killed by electricity annually over the whole of Europe. As regards the United States of America, where electricity is so very extensively employed, I have not been able to find any statistical records. So long ago as I 888 Brown estimated that during the past five years some 200 people had been killed by handling live electric wires. . One must remember that in America life is held very cheap, and that safeguards and protective legislation tend to be regarded as undue restrictions upon industry and commerce. I imagine that not fewer than 200 persons are accidentally killed by electric currents every year in America. As a rule, only a single person is killed by electricity in any single accident; but in an accident occurring in 1909 at Olginate, a village in Lombardy, ten people were killed outright by a three-phase current at 3000 volts, one was saved by artificial respiration, and about a dozen more were severely injured (Hoest).

The interest of men of science, of physicians and pathologists, in such deaths was first shown in France. In 1882 the celebrated French medico-legal expert and pathologist, Brouardel, made a careful post-mortem examination of a man killed in Paris at the Tuileries by a 250 -volt alternating current, and he decided that death was fulminating, due to the electric discharge, and directly caused by arrest of the heart. Bouriot at the same time examined a second and similar case post mortem and came to the conclusion that death was due to violent excitation of the vagus nerve and consequent arrest of the heart, with the result that the heart could not resume its functions, and death by asphyxia followed. In 1885 a man killed instan-

1 From the Goulstonian lectures for x9r3. delivered before the Royal College of Physicians of Lendon by Dr. A. T. Jex-Blake.

$$
\text { No. } 2279 \text {, vOL. 9I] }
$$

taneously by electric shock at the Health Exhibition in London was examined forty hours after death by Sheild and Delépine. Rigor mortis was marked; extreme fluidity of the blood was observed, even the right heart being free from clots. The authors came to the conclusion that "No doubt the vital spots at the base of the brain are in such cases markedly implicated."

During the last twenty years a great many postmortem examinations have been made in cases of sudden death by electric shock. Burns of greater or less superficial extent are generally seen at the points where the electric current has entered and left the body. In the second place, abnormal fluidity of the blood has often been found post mortem; in this, those cases of sudden death by electric shock resemble cases of sudden death by asphyxia. In the third place, no pathological changes are regularly found in the heart muscle, although there are good reasons for believing that in most instances death is directly due to paralysis of the heart. In the fourth place, the central nervous system often shows neither macroscopical nor microscopical changes of importance, except in the cases where relatively large quantities of electricity have passed through the body for long periods of time. In a word, the post-mortem evidence as to the cause of death by electric currents in industrial accidents is generally negative, but may suggest asphyxia in some cases, in others organic vascular and nervous lesions in the brain and cord.

It is upon the evidence obtained by the experimental electrocution of animals that most of our knowledge as to the modes of death by electric shock rests. No electrical apparatus capable of producing currents strong enough to kill animals was invented before about the middle of the eighteenth century. At that time electricity suddenly developed into a popular and spectacular science in France and Germany, just as in the middle of the nineteenth century table-turning, spiritualism, and clairvoyańce were popularly taken up all over England and America with the greatest energy. In neither case was much real scientific progress made by this arousal of popular interest; birds, beetles, and other living creatures were electrocuted by frictional electricity by Gordon (1745), Gralath (i746), Nollet (1749), and many others (Benjamin). It was noted that the birds exhibited ecchymoses where the electric sparks struck them, much like the ecchymoses seen on persons killed by lightning (Nollet). Priestley in 1767 killed kittens and dogs with the discharges of condensers, and tried without success to resuscitate a kitten by artificial respiration, distending the lungs by blowing with a quill into the trachea. Abildgaard (1775), using condensers and I eyden jars, tried without success to electrocute a three-months-old foal; he succeeded in killing cocks and hens by electric discharges sent through the head, and made the important observation that fow!s treated in this way and to all appearances dead could be brought back to life by electric shocks sent through the body from breast to back. but remained dead if not treated in this manner. To mention only a few out of many of those who have since made similar investigations:-

In 1885 Mann made some very interesting experiments on the effects of electricity on the action of the human heart. He applied the electrotes to the precordia and back, and found that a slow'v alternating current of from 15 to 30 milliamperes did not prejudice the heart's action.

In 1885 , and further in 1887 , d'Arsonval made some interesting remarks on deaths caused by industrial electric currents, advancing the views as to their mode of production that he has continued to hold faithfully 
ever since. These deaths, he said, were brought about in one of two ways:-

(I) By direct action, the mechanical effect or disruptive action of the electric current on the tissues; or

(2) By indirect or reflex action on the nervous centres.

In the first case death is final; in the second it is often apparent only, so that the victim may recover if treated by artificial respiration immediately after receiving the shock. Most of the victims of industrial electric accidents had died of asphyxia, he believed. The alternative view that these deaths were due to cardiac failure was first emphasised in 1890 by Tatum and his is the view very generally held at the present time. It was put on a more scientific basis in 1898 by Prevost, who showed that the cardiac failure was the result of fibrillation or fibrillary tremulation of the muscle of the heart, the German Herzdelirium, investigated in $185^{\circ}$ by $\mathrm{Hoffa}$ and Ludwig. The extremely well-designed and well-executed experiments of Prevost and Battelli (1899) proved the great importance of cardiac fibrillation in causing the death of animals of various kinds when exposed to the passage of electric currents through different parts of their bodies. They also illustrated the various effects of electric currents of different varieties-alternating, continuous, sudden discharges from condensers and induction coils-on these animals, and proved that when apparently killed by a current at a low voltage, animals might be brought to life again by the shock of the much stronger currents forced through their bodies by the application of high voltages. These authors also demonstrated that while an alternating current with a frequency of $i_{50}$ alternations a second might be fatal to dogs at an E.M.F. of only ${ }_{5} 5$ to 25 volts, when the alternations were increased to I 720 a second, no fewer than 400 volts were required to produce death. Using high-frequency currents with from 400,000 to $\mathrm{I} .000,000$ alternations a second, d'Arsonval (1893) found he could stand the passage of as much as 3 amperes through his body, a current twenty or thirty times as great as that required to kill a human being at the ordinary rates of alternation employed industrially. The experiments of Cunningham (I899), d'Arsonval (I9Io), Weiss and Zacon (I9II), are also worth recording, and have added considerably to our knowledge of death by electric currents. Weiss and Zacon found that chloral anæsthesia gave dogs no protection against electric shocks. With alternating currents given for a few seconds, death would occur when about 70 to Ioo milliamperes traversed the thorax with the heart en route; with continuous currents, death was not caused unless the current was as large as 300 milliamperes, roughly speaking. If, however, smaller electric currents were administered for long periods, it was found possible to produce death bv tetanus and asphyxia; thus currents of 35 to $\Delta 5$ milliamperes were too small to produce cardiac fibrillation, but after about ten minutes' application caused death by continued inability to breathe, and slow asphyxiation. It may be noted that Prevost and Battelli found that dogs were not killed by alternating currents as great as 4 amperes at 1200 volts, passed through the body from one hind leg to the other; the reason being that with this arrangement of the electrodes the rate of flow of electricity through the muscle of the heart was not large enough to cause it to fibrillate.

One may ronclude that living animals of different species are killed bv electricity with very different degrees of facilitv. For example, many experimenters have endeavour to electrocute frogs, but all, I believe, without success, whatever the current used and however it may have been applied. The frog survives electric shocks and the prolonged passage of electric currents at all sorts of voltages--Io, I00, 1000 volts and more-and shocks from induction coils and charged Leyden jars. The only inconveniences it suffers appear to be transient pareses or paralyses, and, in the case of strong currents passed for many seconds or minutes, the formation of burns. The frog is thus immune because its heart always begins to beat again regularly and normally after the passage of the electric current, and because its respiration does the same; and also, as Priestley pointed out in 1767 , because "its constitution enables it to subsist a long time without breathing." At the other extreme of the scale comes the dog, which can be killed with certainty by an alternating current of perhaps $\mathrm{r}_{5}$ volts or 60 milliamperes, if it is applied so as to pass largely through the heart muscle for a couple of seconds only.

As regards the death of human beings, it may be brought about by electric currents in several different ways.

(a) There is no doubt that it might be due to prolonged tetanus of the muscles, which could prevent the performance of respiratory movements, and so lead to death by asphyxia after some minutes. But I am not able to find that it ever has come about in this way as a matter of fact, the victim always being able either to break the contact and interrupt the passage of the current for himself, or to call for help and get the contact broken by somebody else before asphyxia has occurred in this way.

(b) In man primary heart failure is undoubtedly the commonest mode of death by electric currents. The experiments on animals already detailed show that such deaths are.due to fibrillation of the ventricles of the heart. The fibrillation has been seen occurring in the hearts of two criminals electrocuted in America and examined immediately after death (Schumacher); a few minutes later the left ventricle was firmly contracted and empty, while the right ventricle and the auricles were relaxed in diastole and full of blood. It is probable that in the adult man, as in the dog, horse, and ape, fibrillation of the heart, once it is established, is irremediable, practically speaking.

$(c)$ and $(d)$ Death by failure of the respiration while the heart continues to beat, brought about by nervous inhibition, or by failure of both heart and respiration together, is probably not so common in man. There is a great want of evidence on this point; naturally enough, as the people who are present at deaths by electric shock are generally workmen who do not busy themselves with observations of the pulse and the respiration of the victim. A good many cases have been recorded in which death did not occur until ten, twenty, or forty minutes after the shock had been received, and was then apparently due to failure of the respiration to re-establish itself. The experiments upon animals would lead one to believe that such deaths are really due to failure of the respiratory centre in the central nervous system. The postmortem evidence in such cases should suggest death by asphyxia, and such evidence has sometimes been found after death by electric shock.

(e) Brief reference may be made to the fact that a good many cases have been recorded in which the victim of an electric accident has died after a few days or weeks from complications (shock, gangrene, supouration, exhaustion following extensive amputations) arising out of the injuries caused by the electric current.

With alternating currents, death has occurred from shocks at voltages as low as 65 volts, and a good many instances of death at such pressures as Ioo to I20 volts have been recorded. It is only in very exceptional circumstances that these low voltages can cause death; unless the patient's skin is wet and he No. 2.37\%, VOL. $9 \mathrm{I} 7$ 
makes a good contact, not only with the electric conductor, but also through wet boots or clothes (according as he is standing or sitting), with the ground or some other conductor, there is not the smallest chance of death by currents at such low voltages.

As regards continuous currents of electricity, I have not found records of many fatal accidents at voltages below 220 volts, but in one case a direct current at only 95 volts caused death, in another a current at I Io volts. The minimum number of milliamperes required to kill a human being under conditions favourable for killing is not known. Weiss calculates that from 70 to 90 milliamperes of an ordinary alternating current would be enough if the current went through the chest and heart; d'Arsonval states that much less than Ioo milliamperes suffice to kill. Trotter found that continuous currents up to 35 milliamperes, though almost insupportably painful, were not fatal when passing from the hands to the feet. But when very large industrial currents are forced through the body by high voltages, we meet with the paradox that, while small currents may kill instantaneously, large currents are much less fatal. For example, the American electrocutions have shown that alternating currents of 5 or 8 amperes may pass for many seconds through the body without causing permanent arrest of the heart or respiration. In several recorded non-fatal cases of shock by alternating or three-phase currents at ro,ooo volts, it is true that no measurements of the amperes passing through the victims were made, but it is reasonable to suppose that they may have amounted to several amperes. It is plain, then, that currents of a fraction of an ampere mav cause sudden death by throwing the ventricles of the heart into fibrillary contraction, though much larger currents of several amperes do not act thus, and so are not fatal. But I do not know of any examples or experiments to show at what point or amperage the transition from small dangerous to large non-dangerous currents takes place.

So far as one can guess, in the absence of any experimental proof, it seems that a continuous current must be two or three times as strong as an alternating current, to kill a human being. So far as sudden death is concerned, electric currents are dangerous to man in proportion to the degree to which they tend to pass through the heart.

The prognosis in cases of severe electric shock has been very variously estimated. Cunningham (1899), for example, speaks of artificial respiration as "the only, and almost invariably futile, method in vogue in electrical accidents at the present day," for the resuscitation of persons apparently killed by electric shock. The opposite view is held by Lauffer (I9I2), who says "there are few cases of electrical accident where the victim cannot be restored from the electrical shock, if appropriate immediate efforts at resuscitation are instituted."

The treatment--artificial respiration bv Schäfer's or Svlvester's methods - is still that advised by Priestley in 1767 . The importance of getting to work with the artificial respiration without a moment's delay has often been emphasised by those who have had much experience of electrical accidents. No less important is the necessity for continuing artificial respiration until it is certain that death has occurred; rothing less than cooling of the body or the onset of rigor mortis should be considered to be evidence. of death here.

\section{DeATH By LightNiNG.}

Up to the present time, meteorologists have furnished us with singularly little definite knowledge about the electrical properties of lightning strokes and the electrical quantities concerned in their production. They may be summed up as very strong electric currents of very brief duration and very high potential, containing thousands or possibily millions of foot-tons of energy. When human beings are struck, a part at any rate of this energy is converted into heat, producing various bodily lesions in most instances. Death by lightning-stroke is much commoner in most countries than it is in ours. In England and Wales the Registrar-General reported 124 fatal instances of lightning-stroke, I08 in men and sixteen in women, during the ten years 1901-ro, a yearly average of only 12.4 deaths, or 0.36 per million living. In Hungary the annual death-rate from lightning is said to be sixteen per million living (Milham); in Styria and Carinthia about ten per million, in Prussia 4.4 , in France and in Sweden three, in Belgium two, so far as the imperfect statistics available go (McAdie and Henry). In the Urited States of America the annual deathrate per million is high, about ten, in consequence of the frequency of thunderstorms on one hand, and of the lar $\&$ percentage of the inhabitants engaged ir. outdoor labour on the other; about 700 or 800 deaths from lightning were estimated to occur in the United States every year by Henry in Igoo, in a population of seventy-six millions. Many more people are strucl: by lightning than are killed. For example, Jack records an instance in which a church was struck; 300 people were in it, roo were injured and mostly made unconscious, thirty had to take to their beds, but only six were killed. Weber gives an account of ninety-two people struck in Schleswig-Holstein ; ten were killed, twenty paralysed, fifty-five stupefied and seven only slightly affected. In 1905 tent with $25^{\circ}$ people in it was struck, and sixty were left on the ground in various states of insensibility; one was lilled outright, another breathed for some minutes before dying, the rest recovered. As many as eleven and eighteen persons have been killed by a single stroke of lightning. Vincent mentions a stroke that threw down 1200 and killed 556 out of a flock of 1800 sheep.

As to the exact way in which lightning causes death, some experiments of Prevost and Battelli, in which the discharges of induction coils and condensers were employed, seem to show that it is by central inhibition and cessation of the respiration in many cases, in others by cardiac fibrillation and stnppage of the heart. The bodies of persons lilled by lightning exhibit no characteristic pathological changes except the production of burns and the curious subcuticular or subcutaneous stainings known as. "lightning figures," that often imitate the fronds of ferns or leaves or branches of trees, and have given rise to a deal of baseless speculation as to their mode of production. Among the most interesting of the other and far rarer post-mortem lesions observed are lacerations of the soft tissues and fractures of the bones. The exact mechanism by means of which lightning lacerates tissues and fractures bones is obscure. In cases where the heel is lacerated and the os calcis comminuted, one may perhaps imagine that an extra development of heat and steam has taken place here, with the result that the electric discharge has, so to speak, blown its way out of the body. The example described by Clark and Brigham proves that enough heat may be developed in so deeply situated a bone as the orbital plate of. the frontal bone to char it, so that it is not unreasonable to suppose that small steam explosions mav result if the lightning develops a less degree of heat in a moist tissue. But it is not auite easy to imagine how the tibia and fibula could be broken, without showing any external injury, as in Penfold's case, if the frac- 
tures were caused by small steam explosions taking place inside these bones. Yet there is no alternative explanation to offer. For I do not think it is imaginable that any known forces of electric attraction or repulsion could exert enough violence to break bones. At any rate, the physicists appear to know nothing of electric forces of the magnitude that would be required here. In a few well-recorded instances which are extraordinary almost to the point of being incredible, strokes of lightning have effected amputations.

Unless sudden death follows, the probability that a person struck by lightning will recover is large; Dechambre collected 365 instances in which the immediate effects of the stroke were survived, and found that only fifteen of these victims died subsequently from late effects of the lightning. It seems to be very generally assumed that immediate treatment would improve the prognosis considerably, and that many of the people killed by lightning are only apparently dead, and still capable of recovery if properly treated during the next few minutes. I do not know of any statistical evidence to prove this point.

At the present day only general advice can be given, as the accumulated records have shown that no place above ground is completely protected against lightning. It is certainly safer to be indoors than out, and a large house is much safer than a shanty. The windows and doors of the room in which one is should be shut, and one should keep away from the walls, and particularly from the fireplace, because, when a chimney-stack is struck, the contents of the chimney and the fireplace are often blown out into the room and cause bodily injuries. A great many people have been struck in sheds and barns, especially when they have been near doors or windows, or in currents of air. Turley recommended the centre of a railway carriage at a distance from the engine as the securest place of all; Schefčik, a feather bed. To take refure in the cellars merely to avoid a thunderstorm is not necessary as a routine, though in exceptional cases it may be advisable.

The advice given by various authors to persons caught out of doors in a thunderstorm is contradictory. It is probably unwise to take shelter in a shed unless one can get out of the way of doors, windows, and draughts while one is in it. A shed containing domestic animals is certainly more dangerous than the open. If one has to remain in the open, there are certain things that should be avoided at any cost. The first of these is the proximity of wire fences, because when such a fence is strucls the electric discharge may be carried along the wires and cause death at a distance from the place actually struck. The second is proximity to such things as hedges, ponds, and streams, isolated trees, crowds of people, and herds of domestic animals. Crowds of people or animals seem to have a mild attraction for lightning, very possibly by virtue of the warmth and dampness they impart to the atmosphere immediately round them. It has often been said that to have had the clothes thoroughly wetted by rain and rendered conducting gives some protection to people who are struck bv diverting the path and violence of the lightning from the body to the clothes. I have found seven well-recorded instances in which the effect of the stroke was to blow all, or practically ail, the wetted clothes off the body, by the generation of steam as I believe. There can be no doubt that a part of the energy of the lightning was expended on the clothes in these cases, but three of the seven victims were killed notwithstanding. So the protection of wet clothes cannot be considered at all complete.

So far as treatment is concerned, persons struck NO. 2279 , VOL. 9I] and apparently killed by lightning should at once be given plenty of fresh air, their clothes should be loosened, and artificial respiration by Schäfer's or Sylvester's method should be applied and should be continued until either recovery occurs or cooling of the body and rigor mortis show conclusively that death has taken place. In the medical writings of from fifty to two hundred years ago one often sees bleeding recommended, and this might well be of service in those cases of lightning-stroke in which the heart goes on beating while the respiration stops. If it were immediately-within a few minutes-available, to give strong electric shocks to the præcordia would be well worth trying in desperate cases. As regards other remedies-such as stimulants in all forms, hot or cold applications, the inhalation of pungent vapours-very many have been recommended, but none seem to have met with any success.

\section{UNIVERSITY AND EDUCATIONAL INTELLIGENCE.}

Sheffield.-Mr. W. G. Fearnsides, fellow and lecturer in natural sciences at Sidney Sussex College, and demonstrator in petrology in the University of Cambridge, has been appointed to the Sorby chair of geology.

According to an announcement in the "Political Notes" of The Times, there is reason to believe that the Government has abandoned the intention of introducing this session the Education Bill which was to have embodied the scheme under consideration by Lord Haldane's Cabinet Committee. Every effort is being made to lighten the Government programme so that Parliament may be prorogued at a reasonable date in August.

IT is announced that their Majesties intend to invite to a garden-party at Buckingham Palace on Saturday, July I9, representatives of the teaching profession in London. We understand that invitations will shortly be issued to responsible head-teachers and principals of schools, institutes, and colleges of every type constituting the public system of education in the county of London. A special choir of children selected from public elementary schools will sing before their Majesties.

IN support of the foundation of a Western University in Central China, a meeting of members of Parliament was held in the House of Commons on June 26. Canon Lord William Gascoyne-Cecil said that nothing is being asked for out of the pocket of the British taxpayer. The suggestion is that the British Government should forgo part of the Boxer indemnity. We learn from The Times that it was pointed out that the Boxer indemnity claimed by Great Britain amounted to more than $7,000,000 l .$, and of that amount only 199,00ol. has been paid. A sum of $250,000 l$. spread over a long period would meet the cost of the new University. A motion that a deputation be appointed to urge upon the Prime Minister the desirability of a Government grant, either out of the Boxer indemnity fund or otherwise, towards the establishment of the proposed University was agreed to.

THE Board of Education has issued (Cd. 6866) the regulations, which will come into force on August $\mathrm{I}$, for university tutorial classes in England and Wales. The Board will be prepared to make special grants in aid of part-time courses in subjects of general as distinct from vocational education, given under the educational supervision either of a university or uni- 